\title{
Improvement of cytomegalovirus pp65 DNA vaccine efficacy by co-administration of siRNAs targeting BAK and BAX
}

\author{
JIXIAO LIU $^{1 *}$, KEKE FENG $^{2 *}$, LU ZHAO $^{1}$, HAINING LUO $^{1}$ and YINGJUN ZHU ${ }^{1}$ \\ ${ }^{1}$ Department of Gynecology, Tianjin Obstetrics and Gynecology Center Hospital, Tianjin 300052; \\ ${ }^{2}$ Department of Neurosurgery, Huanhu Hospital, Tianjin 300060, P.R. China
}

Received January 8, 2016; Accepted January 26, 2017

DOI: 10.3892/etm.2017.4385

\begin{abstract}
The efficacy of DNA vaccines may be improved by small interfering (si)RNA adjuvants targeting pro-apoptotic genes. The aim of the present study was to investigate the capacity of siRNAs targeting B-cell lymphoma 2 homologous antagonist killer (BAK) and B-cell lymphoma 2-associated X protein (BAX) to improve the efficacy of a cytomegalovirus (CMV) vaccine. BALB/c mice were divided into four groups $(\mathrm{n}=18$ in each): unimmunized and immunized with pcDNA 3.1-pp65 expressing CMV $65 \mathrm{kDa}$ matrix phosphoprotein and BAK + BAX siRNAs, pcDNA 3.1-pp65 and control siRNA, or control pcDNA 3.1 and BAK + BAX siRNAs. Immuniza tions were performed twice with an interval of 3 weeks. $\mathrm{CMV}$-specific mouse splenocyte interferon (IFN)- $\gamma$ secretion was assessed by ELISPOT; furthermore, an in vivo cytotoxic $\mathrm{T}$ lymphocyte assay was performed 2 weeks after the last immunization. After lethal CMV challenge of the mice, body weight, virus titers in the spleens and salivary glands as well as survival were recorded. The amount of splenocytes secreting IFN- $\gamma$ in response to CMV pp65 peptides and specific lysis of peptide-pulsed target cells were significantly higher in mice administered pcDNA3.1-pp65 and BAK + BAX siRNAs than those in mice administered pcDNA3.1-pp65 and control siRNA $(\mathrm{P}<0.05$ for each). After the virus challenge, the virus titers in the spleens and salivary glands of mice given pcDNA3.1-pp65 and BAK + BAX siRNAs were significantly lower than those in mice immunized with pcDNA3.1-pp65 and control siRNA $(\mathrm{P}<0.05$ for each). Furthermore, mice immunized with pcDNA 3.1-pp65 and control siRNA or BAK + BAX siRNAs survived for longer, and at 21 days after lethal CMV challenge, 66 and $100 \%$ of these mice survived, respectively. These mice also
\end{abstract}

Correspondence to: Dr Yingjun Zhu, Department of Gynecology, Tianjin Obstetrics and Gynecology Center Hospital, 156 Third Road of Nankai, Tianjin 300052, P.R. China

E-mail: yingjunzhutj@163.com

*Contributed equally

Key words: cytomegalovirus, BAK, BAX, DNA vaccine, cytomegalovirus $65 \mathrm{kDa}$ matrix phosphoprotein, small interfering RNA experienced less weight loss compared with mice immunized with pcDNA3.1-pp65 and control siRNA $(\mathrm{P}<0.05)$. In conclusion, intradermal administration of siRNAs targeting BAK and BAX improved the efficacy of CMV pp65 DNA vaccine.

\section{Introduction}

Human cytomegalovirus (HCMV) is the most common congenital infection worldwide (0.2-2.0\% of all pregnancies). Congenital $\mathrm{HCMcV}$ infection often results in long-term consequences to the developing fetus, including mortality, and HCMV is the leading viral cause of neurodevelopmental abnormalities and other birth defects in children $(1,2)$. At present, no suitable treatment is available for HCMV infection, and an effective preventive measure is urgently sought. The development of a vaccine to prevent HCMV infection was assigned the highest priority by the US Institute of Medicine (3-6), but no candidate vaccine is currently under consideration for licensing.

The innate and humoral immune responses to CMV contribute to controlling the infection; however, in latently infected individuals, the cellular immune response is required to control latency and impede viral replication (7). In the protection against $\mathrm{CMV}$, cellular immune responses are important (8), and a high frequency of CMV-specific CD8 ${ }^{+}$ cytotoxic T-lymphocyte responses has been observed in CMV-seropositive individuals (9). In fact, up to $10 \%$ of all circulating $\mathrm{CD}^{+} \mathrm{T}$ cells may be directed towards $\mathrm{CMV}$, which is a high number considering the large diversity of pathogens encountered during any individual's lifetime (10).

Dendritic cells (DCs) are mononuclear phagocytes linking innate and adaptive immunity, and are likely to be necessary for CMV control. DCs are critical for the induction of cellular immunity because they are uniquely efficient activators of naive $\mathrm{T}$ cells during their first encounter with a pathogen. DC death can reduce the interaction between antigen-presenting cells (APC)s and lymphocytes, causing $\mathrm{T}$ cells to downregulate anti-apoptotic molecules and potentially upregulate pro-apoptotic molecules (11). This process would likely reduce the number of activated antigen-specific $\mathrm{CD}^{+} \mathrm{T}$ cells. A variety of anti-apoptotic factors have been reported to enhance dendritic cell survival and T-cell immune responses (12).

Small interfering (si)RNA is an effective means of silencing gene expression, and it may be possible to use 
this technique to attenuate immune responses to vaccines. For instance, silencing of key pro-apoptotic genes may prolong dendritic cell life. In fact, co-administration of DNA encoding anti-apoptotic proteins may significantly enhance DNA vaccine potency. However, the use of DNA encoding anti-apoptotic proteins, such as B-cell lymphoma extra large, raises significant concerns, as without sufficient targeting, anti-apoptotic proteins may have oncogenic effects. The use of siRNA targeting pro-apoptotic proteins, however, may alleviate these concerns due to the transient nature of the silencing caused by siRNA in mammalian cells (13). siRNAs do not integrate into the genome and, thus, cause no permanent genetic changes. This technique has been previously applied to attenuate the immune response to vaccines in experimental animal models (14-16). Dharmapuri et al (14) reported the use of B-cell lymphoma 2 (Bcl-2) homologous antagonist killer (BAK) 1 or Caspase 8 siRNA to enhance immunogenicity of a DNA vaccine targeting human epidermal growth factor 2 . In a mouse model, this technique reduced spontaneous tumor progression (14). Song et al (15) used siRNA to reduce the expression of suppressor of cytokine signaling during immunization against human immunodeficiency virus (HIV) and successfully improved the potency of HIV DNA vaccination. Kim et al (16) also previously reported that co-administration of the human papilloma virus DNA vaccine, pcDNA 3-E7/green fluorescence protein (GFP), with adjuvant BAK $+\mathrm{Bcl}-2$-associated $\mathrm{X}$ protein $(\mathrm{BAX})$ siRNA significantly increased the number of $\mathrm{GFP}^{+}$dendritic cells in the draining lymph nodes and increased the E7-specific CD8 ${ }^{+} \mathrm{T}$-cell immune response of vaccinated mice.

$\mathrm{BAX}$ and BAK are Bcl-2 family proteins that are crucial components of the intrinsic apoptotic pathway (16). The present study sought to investigate the capacity of BAK and BAX siRNA to improve immunogenicity of a mouse CMV (MCMV) vaccine. As CMV-infected cells express MCMV 65 kDa matrix phosphoprotein (pp65) in early as well as late stages of infection, it represents an appropriate vaccine target and was selected as a model antigen (17-19). Of note, $\mathrm{T}$ cells specific for CMV-pp65, a principal target for cytotoxic $\mathrm{T}$ lymphocytes (CTLs), have been reported to prevent CMV complications in hematopoietic cell transplant recipients (17,19-21). Thus, in the present study, the potency of intradermal co-administration of DNA vaccines encoding MCMV-pp65 antigen combined with BAK and BAX siRNA was assessed.

\section{Materials and methods}

Animals. A total of 72 healthy BALB/c mice (H-2d) aged, 8 weeks with an average weight of $14 \mathrm{~g}$, were purchased from the Tianjin Medical University Laboratory Animal Center (Tianjin, China) and were maintained under specific pathogen-free conditions prior to infection. Mice were housed in individually ventilated cages with free access to food and water in a temperature- and humidity-controlled room maintained under filtered positive-pressure ventilation with a 12-h light/dark cycle. All procedures and animal experiments were approved by the Animal Care and Use Committee of Tianjin Central Hospital of Gynecology and Obstetrics (Tianjin, China).
Cells and virus. The MCMV Smith strain was obtained from the obstetrics laboratory of Tongji Hospital (Tongji Medical College, Huazhong University of Science \& Technology, Wuhan, China) and was propagated in NIH 3T3 cells (CRL 1658; American Type Culture Collection, Manassas, VA, USA). 3T3 cells were cultured in Minimal Essential Medium containing $10 \%$ fetal calf serum (FCS; Takara Biotechnology Co., Ltd, Dalian, China). The virus obtained from the cell culture was propagated and purified by ultracentrifugation as described by Brune et al (22). The virus was passaged in $\mathrm{BALB} / \mathrm{c}(\mathrm{H}-2 \mathrm{~d})$ mice 14 times to enhance virulence, and then isolated from the salivary glands of infected mice (23). This virus was referred to as salivary gland-derived (SG)-MCMV for challenge experiments. Challenge was performed with virus stock at $3 \mathrm{xLD}_{50}$.

Construction of the DNA vaccine plasmid. Plasmid pp65 was constructed by cloning the polymerase chain reaction (PCR) products of the pp65 gene (GenBank accession no. EF531301) from the MCMV Smith strain into the plasmid expression vector pcDNA 3.1/myc-His B (Invitrogen; Thermo Fisher Scientific, Inc., Waltham, MA, USA). PCR amplifications for pp65 genes were performed using the following paired sense and anti-sense primers: 5'-GCaagcttCATGTCGGTCAACGT TTACT-3' (containing HindIII site; indicated by lower case letters) and 5'-GCtctagaGGCTCTGTCTGTTTGTCTATG-3' (containing XbaI site; indicated by lower case letters). The accuracy of the constructs was confirmed by DNA sequencing. The plasmid was propagated in Escherichia coli XL1-blue bacteria and purified using NucleoBond Xtra Maxi purification kits (Macherey-Nagel, Düren, Germany).

Vaccine preparation. BAK and BAX siRNAs were synthesized and DNA/siRNA-coated gold particles were produced as previously described (16).

Animal immunization. The mice were divided into four experimental groups containing 18 mice in each. The DNA/ siRNA-coated gold particles $(1 \mu \mathrm{g}$ DNA and $0.1 \mu \mathrm{g}$ siRNA per bullet) were delivered to the shaved abdominal region of the mice using a helium-driven gene gun (Bio-Rad Laboratories, Inc., Hercules, CA, USA) with a discharge pressure of 400 pounds per square inch (16). Three groups of mice were immunized with either $2 \mu \mathrm{g}$ pcDNA 3.1-pp65 expressing pp65 mixed with 0.2 $\mu \mathrm{g}$ BAK + BAX siRNA (pcDNA 3.1-pp65 with BAK+BAX siRNA group), $2 \mu \mathrm{g}$ pcDNA 3.1-pp65 with $0.2 \mu \mathrm{g}$ control siRNA (pcDNA 3.1-pp65 with control siRNA group), or $2 \mu \mathrm{g}$ control pcDNA 3.1 with $0.2 \mu \mathrm{g}$ BAK + BAX siRNA (negative control group). One group remained unimmunized (unimmunized group). Immunizations were performed twice with an interval of 3 weeks.

Peptides. Synthetic peptides spanning the CMV pp65 were purchased from Melone Pharmaceutical Co., Ltd. (Dalian, China; purity, $>90 \%$, determined by high-performance liquid chromatography). Lyophilized peptides were resuspended in $100 \%$ dimethyl sulfoxide at $100 \mathrm{mg} / \mathrm{ml}$, stored at $-80^{\circ} \mathrm{C}$ and diluted in R-10 medium (RPMI-1640 medium supplemented with $100 \mathrm{U} / \mathrm{ml}$ penicillin, $100 \mu \mathrm{g} / \mathrm{ml}$ streptomycin, $0.1 \mathrm{mM}$ nonessential amino acids, 0.01 M HEPES, 2 mM glutamine 
and $10 \%$ heat-inactivated FCS. All were purchased from Melone Pharmaceutical Co., Ltd., (Dalian, China) for use. Dimethyl sulfoxide concentrations in all assay mixtures were $\leq 0.1 \%(\mathrm{vol} / \mathrm{vol})$.

Preparation of splenocytes. Fourteen days after the last immunization, four mice in each group were euthanized and their spleens were removed, homogenized and washed with saline supplemented with $2 \%$ FCS. Erythrocytes were removed by washing in $0.83 \% \mathrm{NH}_{4} \mathrm{Cl}$ solution. Isolated cells were cultivated in complete RPMI-1640 medium containing 10\% FCS, $2 \mathrm{mM}$ L-glutamine, $100 \mathrm{mg} / \mathrm{ml}$ streptomycin and $100 \mathrm{U} / \mathrm{ml}$ penicillin.

Interferon (IFN)- $\gamma$ ELISPOT assay. Secretion of IFN- $\gamma$ from splenocytes described above was detected by ELISPOT using a pre-coated ELISPOT kit (DKW12-2000-048; Dakewei, Dalian, China). According to the manufacturer's instructions, 96-well polyvinylidene fluoride plates (Millipore, Bedford, MA, USA) were coated with $100 \mu \mathrm{l}$ of $10 \mu \mathrm{g} / \mathrm{ml}$ rat anti-mouse IFN- $\gamma$ antibody in PBS and incubated at $4^{\circ} \mathrm{C}$ overnight. Subsequently, $5 \times 10^{5}$ lymphocytes were added to each well in triplicate and stimulated with $4 \mu \mathrm{g} / \mathrm{ml} \mathrm{CMV} \mathrm{pp65} \mathrm{synthetic}$ peptides, followed by incubation at $37^{\circ} \mathrm{C}$ for $20 \mathrm{~h}$. The lymphocytes were then removed and $100 \mu l$ biotinylated anti-mouse IFN- $\gamma$ antibody was added to each well, followed by incubation at $37^{\circ} \mathrm{C}$ for $1 \mathrm{~h}$. Subsequently, $100 \mu \mathrm{l}$ diluted streptavidin-horseradish peroxidase conjugate solution was added, followed by incubation at room temperature for $1 \mathrm{~h}$. Finally, the plates were treated with $100 \mu 1$ 3-Amino-9-ethylcarbazole substrate solution (cat. no. A5754, Sigma-Aldrich; Merck KGaG, Darmstad, Germany) and incubated at room temperature for $25 \mathrm{~min}$ in the dark. The reaction was stopped by washing with demineralized water. The plates were air-dried at room temperature and read using an ELISPOT reader (Bioreader 4000; Bio-Sys GmbH, Karben, Germany). Medium backgrounds were consistently $<10$ spots per $5 \times 10^{5}$ splenocytes.

In vivo CTL assay. CTLs were assessed in vivo as previously described (24). In brief, splenocytes from naive BALB/c mice (H-2d) were equally divided into two parts and incubated with carboxyfluorescein (CFSE) at either a low $(0.5 \mu \mathrm{M})$ or a high concentration $(5 \mu \mathrm{M})$. The CMV pp65 synthetic peptides were added to the high CFSE group at a final concentration of $5 \mu \mathrm{M}$, while the cells in the CFSE-low group were not stimulated. CFSE-high and CFSE-low cells were mixed (1:1) and $2 \times 10^{7}$ mixed cells were given to the immunized mice two weeks after the final immunization (four mice in each group) via tail vein injection. After $20 \mathrm{~h}$, spleens were harvested from the immunized mice and the relative proportion of CFSE-high and CFSE-low cells was determined by flow cytometry using a PAS (Sysmex Partec, Görlitz, Germany) instrument and analyzed using FlowMax software (Sysmex Partec). Percent-specific lysis was calculated as [1-(r-unprimed/r-primed)]x100\%, where $r=\%$ CFSE-low/\%CFSE-high for each mouse $(25,26)$ and primed indicates the samples challenged by CMV pp65 synthetic peptides.

Virus challenge. Fourteen days after the second immunization, mice ( $n=10$ in each group) were challenged with a lethal dose ( $3 \times 10^{5}$ PFU, $200 \mu \mathrm{l} /$ mouse) of SG-MCMV by intraperitoneal injection, as previously determined (3). Body weights and survival rates of mice were recorded within 21 days after virus challenge.

Determination of the virus titer in infected organs. Five days after the virus challenge, four mice from each group were sacrificed and the spleens were retrieved. The six remaining mice in each group were monitored for weight loss and survival. On day 21 post-challenge, four mice were randomly selected from the remaining six mice and the salivary glands were retrieved.

Spleens and salivary glands were homogenized in 1:10 w/v MEM containing $10 \%$ FCS. The homogenized fluids were centrifuged at $32,000 \times \mathrm{g}$ for $10 \mathrm{~min}$ at room temperature and the supernatants stored in aliquots at $-80^{\circ} \mathrm{C}$. Viral loads were determined using a plaque-forming cell assay. In brief, organ homogenates were serially diluted 10 -fold and each dilution was used to infect 3T3 cells cultured in 48-well plates. Infections were performed in triplicate and to each well, to provide a final volume of $100 \mu \mathrm{l}$ viral suspension. After $1 \mathrm{~h}$ of absorption, the supernatant was aspirated and $0.5 \mathrm{ml}$ viscous medium was added to each well. After incubation for 4-6 days, viral plaques were counted and the viral plaque-forming units (PFU) per milliliter were calculated.

Statistical analysis. All statistical analyses were performed using SPSS 17.0 software for Windows (SPSS Inc., Chicago, IL, USA). Values are expressed as the mean \pm standard deviation. Statistical significance was evaluated by the independent-samples $t$-test or one-way analysis of variance. $\mathrm{P}<0.05$ was considered to indicate a statistically significant difference.

\section{Results}

siRNAs targeting the pro-apoptotic genes $B A K$ and $B A X$ promote splenocyte IFN- $\gamma$ secretion in vaccinated mice. To investigate the capacity of siRNAs targeting the pro-apoptotic genes BAK and BAX to improve the efficacy of a DNA vaccine for $\mathrm{CMV}, \mathrm{BALB} / \mathrm{C}$ mice were immunized with pcDNA 3.1-pp65 and BAK + BAX siRNAs, pcDNA 3.1-pp65 and control siRNA, and pcDNA 3.1 and BAK + BAX siRNAs as a negative control, and another group of mice remained unvaccinated. Fourteen days after the last immunization, the splenocytes were collected from four mice in each group. Splenocyte IFN- $\gamma$ secretion in response to CMV pp65 peptides was assessed by ELISPOT (Fig. 1). The number of splenocytes induced to secrete IFN- $\gamma$ in response to CMV peptides was significantly higher in mice administered pcDNA 3.1-pp65 with $\mathrm{BAK}+\mathrm{BAX}$ siRNA $\left(636 \pm 49\right.$ spots $/ 5 \times 10^{5}$ splenocytes; range, $603-731$ spots $/ 5 \times 10^{5}$ splenocytes) than that in mice administered pcDNA 3.1-pp65 and control siRNA $372 \pm 43$ spots $/ 5 \times 10^{5}$ splenocytes; range, $313-511$ spots $/ 5 \times 10^{5}$ splenocytes; $\mathrm{P}<0.05)$. By contrast, only $<20$ spots $/ 5 \times 10^{5}$ splenocytes were detected in the unimmunized mice and the negative control mice.

siRNAs targeting the pro-apoptotic genes $B A K$ and $B A X$ promote $C M V$-specific CTL responses of immunized mice. Two weeks after the final immunization, mice were re-stimulated by naive splenocytes that had been pulsed ex vivo with $\mathrm{CMV}$ 


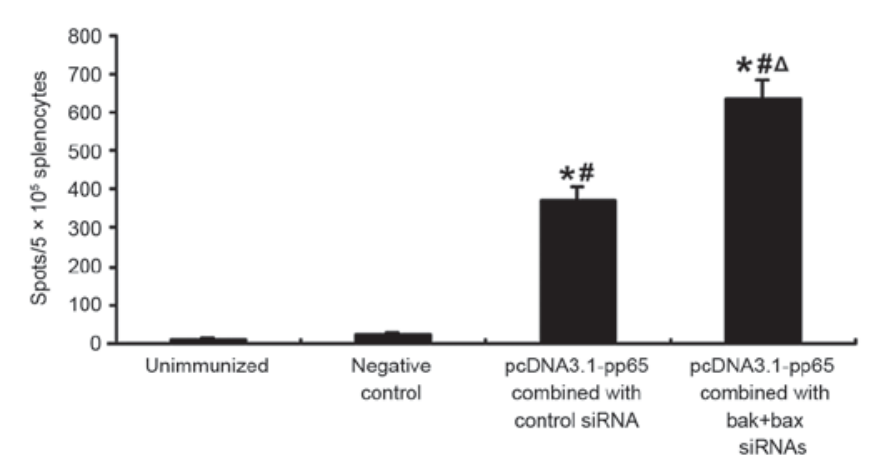

Figure 1. Splenocyte IFN- $\gamma$ secretion following immunization with CMV pp65 DNA vaccine combined with or without BAK + BAX siRNAs. Mice were immunized with pcDNA 3.1-pp65 and BAK + BAX siRNAs; pcDNA 3.1-pp65 and control siRNA; pcDNA 3.1 with BAK + BAX siRNAs (negative control); or no vaccine (unimmunized group). Fourteen days after the last immunization, splenocytes were collected from mice and stimulated with $4 \mu \mathrm{g} / \mathrm{ml}$ synthesized CMV pp65 peptide. Splenocyte IFN- $\gamma$ secretion was assessed by ELISPOT. Values are expressed as the mean \pm standard deviation $(n=4$ in each group). ${ }^{*} \mathrm{P}<0.05$ vs. unimmunized group; ${ }^{*} \mathrm{P}<0.05$ vs. negative control; ${ }^{\Delta} \mathrm{P}<0.05$ vs. pcDNA 3.1-pp65 combined with control siRNA. CMV, cytomegalovirus; IFN, interferon; BAK, B-cell lymphoma 2 homologous antagonist killer; BAX, B-cell lymphoma 2-associated X protein; siRNA, small interfering RNA.

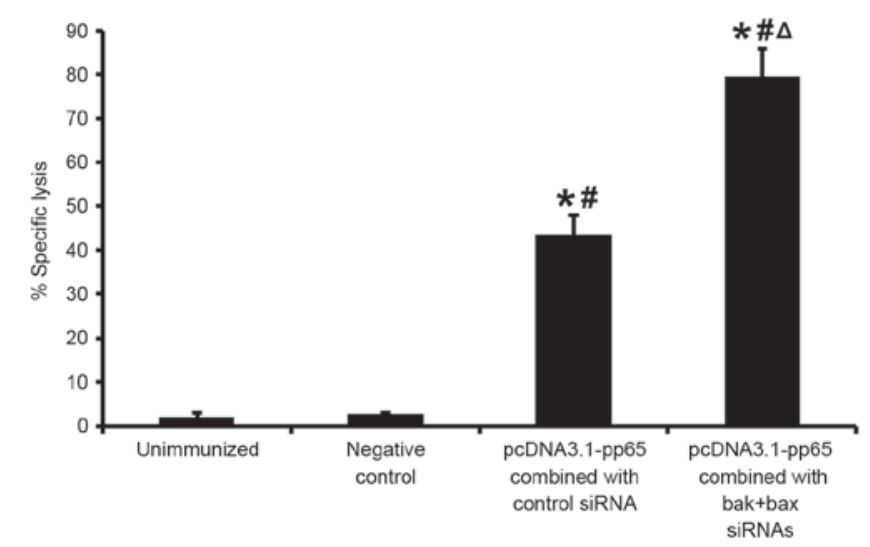

Figure 2. In vivo CTL responses following immunization with CMV pp65 DNA vaccine with or without BAK + BAX siRNAs. In vivo CTL responses were assessed by measurement of the relative proportion of $\mathrm{CFSE}_{\text {high }}$ and $\mathrm{CFSE}_{\text {low }}$ cells by flow cytometry. Values are expressed as the mean \pm standard deviation. ${ }^{*} \mathrm{P}<0.05$ vs. unimmunized group; ${ }^{*} \mathrm{P}<0.05$ vs. negative control; ${ }^{\Delta} \mathrm{P}<0.05$ vs. pcDNA 3.1-pp65 combined with control siRNA. CTL, cytotoxic T lymphocytes; BAK, B-cell lymphoma 2 homologous antagonist killer; BAX, B-cell lymphoma 2-associated X protein; siRNA, small interfering RNA; CFSE, carboxyfluorescein.

pp65 peptide. CTL responses of these splenocytes were measured in vivo after $20 \mathrm{~h}$. Specific lysis of peptide-pulsed target cells by the splenocytes of mice immunized with pcDNA 3.1-pp65 and control siRNA $(43.5 \pm 4.5 \%)$ was higher than that in unimmunized mice $(2.12 \pm 0.87 \%)$ or mice administered pcDNA 3.1 and BAK + BAX siRNAs $(2.91 \pm 0.13 \%$; $\mathrm{P}<0.05)$, and specific lysis was significantly greater in mice immunized with pcDNA 3.1-pp65 and BAK+BAX siRNAs $(79.54 \pm 6.2 \%)$ than in those treated with pcDNA 3.1-pp65 combined with control siRNA (43.5 $\pm 4.5 \%$; P $<0.05$; Fig. 2).

siRNAs targeting BAK and BAX improve the efficacy of CMV pp65 DNA vaccine. Two weeks after the final immunization, mice were challenged with a lethal dose of SG-MCMV

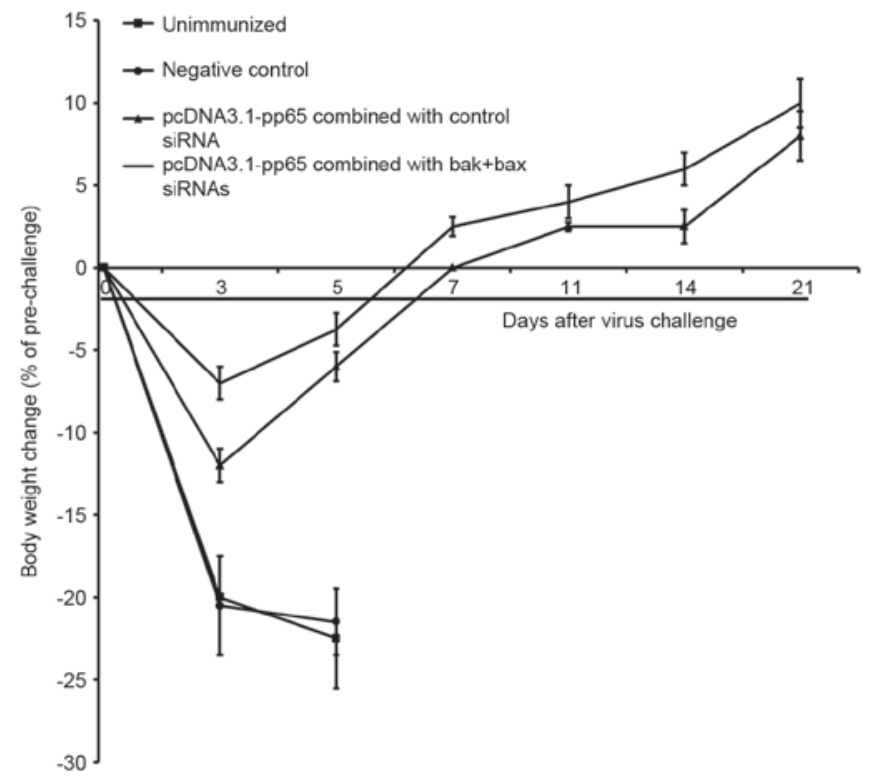

Figure 3. Body weight changes after CMV challenge of mice. Two weeks after the final immunization, 6 mice in each group were challenged with a lethal dose $\left(3 \times \mathrm{XD}_{50}\right)$ of $\mathrm{CMV}$ and the body weights were determined within 3 weeks after the challenge. Values are expressed as the mean \pm standard deviation. CMV, cytomegalovirus; BAK, B-cell lymphoma 2 homologous antagonist killer; BAX, B-cell lymphoma 2 -associated X protein; siRNA, small interfering RNA.

$\left(3 \times L_{50}\right)$. The survival rate and body weight were monitored over 21 days after the virus challenge. Within the first few days after the challenge, the acute phase of infection, significant weight loss was observed in the unimmunized group and negative control group, and all of these mice died within 7 days (Fig. 3). Mice immunized with pcDNA 3.1-pp65 and control siRNA or BAK + BAX siRNA survived for longer, and at 21 days after the virus challenge, 66 and $100 \%$ of these mice survived, respectively (Fig. 3). These mice also experienced less marked weight loss, with the weight returning to the baseline weight within 7 days of viral challenge (Fig. 3).

MCMV titers in the spleens and salivary glands of mice after lethal challenge. During SG-MCMV infection, the viral load in the spleens of mice was reported to peak on day 5 post-infection, and decrease rapidly after the acute phase (27). In the present study, spleens of 4 mice from each group were harvested 5 days post-infection and viral titers were determined (Table I). On day 5 after viral infection, the viral titers in the spleens of unimmunized mice and mice in the negative control group reached 5.2 $\log 10$ and 5.1 $\log 10 \mathrm{PFU} / \mathrm{ml}$, respectively. However, in mice immunized with pcDNA 3.1-pp65 and control siRNA, the viral titers in the spleens were significantly lower $(3.6 \mathrm{Log} 10 \mathrm{PFU} / \mathrm{ml}$; $\mathrm{P}<0.05)$. Compared with the other three groups, the titers were decreased in mice immunized with pcDNA 3.1-pp65 and BAK + BAX siRNAs (2.4 Log10 PFU/ml; P<0.05).

The salivary gland is another important organ for virus replication, latency and dissemination. By day 21 after viral challenge, all unimmunized mice and mice that received mock immunization had died, but the salivary glands obtained from 4 surviving mice from each of the immunized groups were harvested and viral titers were determined (Table I). The 
viral titers detected in the salivary glands of mice that were immunized with pcDNA 3.1-pp65 and BAK + BAX siRNA $\left(10^{2.9} \mathrm{PFU} / \mathrm{ml}\right)$ were lower than those of mice immunized with pcDNA 3.1-pp65 and control siRNA $\left(10^{4} \mathrm{PFU} / \mathrm{ml}\right)$.

\section{Discussion}

The efficacy of DNA vaccines may be improved by co-administration of siRNA targeting pro-apoptotic genes that can prolong the cellular immune response. The present study investigated the capacity of siRNA targeting the pro-apoptotic genes BAK and BAX to improve the efficacy of a vaccine for CMV. It was observed that the gene gun delivery of a CMV pp65 DNA vaccine achieved good immunogenicity in mice. The number of splenocytes secreting IFN- $\gamma$ in response to CMV pp65 peptides and lysis of peptide-pulsed target cells was significantly higher in mice administered pcDNA 3.1-pp65 and $\mathrm{BAK}+\mathrm{BAX}$ siRNA than those in mice administered pcDNA 3.1-pp65 and control siRNA.

At 3 weeks post-immunization, mice were challenged with a lethal dose of MCMV. A reduction in viral load has been suggested to provide significant therapeutic benefits to patients with HCMV disease, for which CMV vaccination is the most practical approach (28). MCMV infects mice intraperitoneally in this experiment, which is also the general site of infection in mice, and during acute infection, it replicates in multiple organs, including the spleen, liver, lung and salivary glands. Viral loads in the spleen and liver peak $\sim 5$ days post-infection and then drop to the limit of detection by 9 days post-infection (29). The spleen is the most important organ for T-cell responses. In the present study, the viral titers in the spleens of mice were tested at 5 days post-infection, revealing that the viral loads in immunized mice were significantly lower than those in unimmunized and negative control mice. Moreover, administration of BAK + BAX siRNAs significantly lowered the viral titers in immunized mice.

This result corresponded with those on the number of IFN- $\gamma$ secreting splenocytes and CTL activity. In addition to mouse spleens, the salivary glands, which are the main organ for CMV replication and latency, were also assessed (29). The residual viral loads in the salivary glands corresponded to those in the spleen.

Furthermore, the body weight of mice varied substantially. Mice immunized with pcDNA 3.1-pp65 and BAK + BAX siRNAs exhibited less weight loss compared with mice immunized with pcDNA3.1-pp65 and control siRNA $(\mathrm{P}<0.05)$ during the first days after the lethal challenge. While all challenged mice lost weight, the pp65 plasmid provided protection, and this protection was more effective when BAK + BAX siRNA was co-administered. Thus, the survival rate, viral titers in organs and body weight changes may be jointly considered to evaluate the protective abilities of the CMV vaccines in such a murine model of lethal-dose viral infection. Co-administration of pp65 vaccine with BAK + BAX siRNAs conferred excellent protection against lethal CMV challenge, confirming that co-administration of adjuvant BAK + BAX siRNA improved the efficacy of this DNA vaccine.

These encouraging results suggested that modifying the function of dendritic cells in vivo by using siRNA technology may enhance DNA vaccine potency. It was previously reported that co-administration of BAK + BAX siRNA with a DNA
Table I. Virus titers in the spleen and salivary glands of mice after lethal challenge.

\begin{tabular}{lcc}
\hline Group & $\begin{array}{c}\text { Spleen virus titer } \\
\left(\log _{10} \text { PFU/ml }\right)\end{array}$ & $\begin{array}{c}\text { Salivary gland virus } \\
\text { titer }\left(\log _{10} \text { PFU/ml }\right)\end{array}$ \\
\hline Unimmunized & $5.2 \pm 0.2$ & $\mathrm{ND}$ \\
Negative control & $5.1 \pm 0.2$ & $\mathrm{ND}$ \\
pcDNA 3 1-pp65 & $3.6 \pm 0.1^{\mathrm{a}, \mathrm{b}}$ & $4.2 \pm 0.2$ \\
combined with & & \\
control siRNA & & $2.9 \pm 0.1^{\mathrm{c}}$ \\
pcDNA 3.1-pp65 & $2.4 \pm 0.2^{\mathrm{a}-\mathrm{c}}$ & \\
combined with & & \\
BAK + BAX siRNAs & & \\
\hline
\end{tabular}

${ }^{\mathrm{a}} \mathrm{P}<0.05$ vs. unimmunized group; ${ }^{\mathrm{b}} \mathrm{P}<0.05$ vs. negative control; ${ }^{\mathrm{c}} \mathrm{P}<0.05$ vs. pcDNA 3.1-pp65 combined with control siRNA. Mice were challenged with a lethal dose of salivary gland-derived mouse cytomegalovirus 3 weeks after the boost. Spleen virus titers at 5 days after the challenge and salivary gland virus titers at 3 weeks after the challenge were measured. Values are expressed as the mean \pm standard deviation ( $n=4$ per group). pcDNA 3.1 combined with BAK + BAX siRNAs was used as a negative control. BAK, B-cell lymphoma 2 homologous antagonist killer; BAX, B-cell lymphoma 2-associated $\mathrm{X}$ protein; siRNA, small interfering RNA; ND, not detected; PFU, plaque-forming units.

vaccine increases the number of antigen-expressing dendritic cells in the lymph nodes, which may contribute to increased numbers of specific $\mathrm{CD}^{+} \mathrm{T}$ cells in vaccinated mice (16). Antigen-expressing dendritic cells not only provide signals to trigger expansion and proliferation of antigen-specific T cells, but may also provide signaling required to reduce T-cell apoptosis. The anti-apoptotic effects of BAK + BAX siRNA may modify the quality and quantity of dendritic cells, leading to increased T-cell activation and enhanced DNA vaccine potency.

However, widespread application of these techniques is limited by operational constraints. While intradermal delivery to APCs via gene gun is an effective system for delivery of siRNA into APCs, allowing for the evaluation of siRNA-based strategies to modify dendritic cells $(30,31)$, this strategy may be difficult to adapt in a clinical setting.

In summary, the cellular immune responses induced by CMV pp65 DNA vaccination may be significantly enhanced by co-administration of BAK + BAX siRNAs. Modifying the function of dendritic cells in vivo using siRNA technology targeting other key pro-apoptotic proteins, such as caspase-3 and -6-9 may also improve the potency of DNA vaccines for cancer and other infectious diseases.

\section{Acknowledgements}

This work was supported by grants from the National Natural Science Fund of China (no. 30801248).

\section{References}

1. Weller TH: The cytomegaloviruses: Ubiquitous agents with protean clinical manifestations. II. N Engl J Med 285: 267-274, 1971. 
2. Pereira L and Maidji E: Cytomegalovirus infection in the human placenta: Maternal immunity and developmentally regulated receptors on trophoblasts converge. Curr Top Microbiol Immunol 325: 383-395, 2008.

3. Morello CS, Kelley LA, Munks MW, Hill AB and Spector DH: DNA immunization using highly conserved murine cytomegalovirus genes encoding homologs of human cytomegalovirus UL54 (DNA polymerase) and UL105 (helicase) elicits strong CD8 T-cell responses and is protective against systemic challenge. J Virol 81: 7766-7775, 2007.

4. Griffiths P, Plotkin S, Mocarski E, Pass R, Schleiss M, Krause P and Bialek S: Desirability and feasibility of a vaccine against cytomegalovirus. Vaccine 31 (Suppl 2): B197-B203, 2013.

5. Arvin AM, Fast P, Myers M, Plotkin S and Rabinovich R National Vaccine Advisory Committee: Vaccine development to prevent cytomegalovirus disease: Report from the national vaccine advisory committee. Clin Infect Dis 39: 233-239, 2004.

6. Sung H and Schleiss MR: Update on the current status of cytomegalovirus vaccines. Expert Rev Vaccines 9: 1303-1314, 2010.

7. Moss $\mathrm{P}$ and Rickinson A: Cellular immunotherapy for viral infection after HSC transplantation. Nat Rev Immunol 5: 9-20, 2005 .

8. Hanley PJ and Bollard CM: Controlling cytomegalovirus: Helping the immune system take the lead. Viruses 6: 2242-2258, 2014.

9. Reap EA, Dryga SA, Morris J, Rivers B, Norberg PK, Olmsted RA and Chulay JD: Cellular and humoral immune responses to alphavirus replicon vaccines expressing cytomegalovirus pp65, IE1, and gB proteins. Clin Vaccine Immunol 14: 748-755, 2007.

10. Crough $\mathrm{T}$ and Khanna R: Immunobiology of human cytomegalovirus: From bench to bedside. Clin Microbiol Rev 22: 76-98, 2009.

11. Opferman JT and Korsmeyer SJ: Apoptosis in the development and maintenance of the immune system. Nat Immunol 4: 410-415, 2003

12. Kim TW, Hung CF, Ling M, Juang J, He L, Hardwick JM, Kumar S and Wu TC: Enhancing DNA vaccine potency by coadministration of DNA encoding antiapoptotic proteins. J Clin Invest 112: 109-117, 2003

13. Mittal V: Improving the efficiency of RNA interference in mammals. Nat Rev Genet 5: 355-365, 2004.

14. Dharmapuri S, Aurisicchio L, Biondo A, Welsh N, Ciliberto G and La Monica N: Antiapoptotic small interfering RNA as potent adjuvant of DNA vaccination in a mouse mammary tumor model Hum Gene Ther 20: 589-597, 2009.

15. Song XT, Evel-Kabler K, Rollins L, Aldrich M, Gao F, Huang XF and Chen SY: An alternative and effective HIV vaccination approach based on inhibition of antigen presentation attenuators in dendritic cells. PLoS Med 3: e11, 2006

16. Kim TW, Lee JH, He L, Boyd DA, Hardwick JM, Hung CF and Wu TC: Modification of professional antigen-presenting cells with small interfering RNA in vivo to enhance cancer vaccine potency. Cancer Res 65: 309-316, 2005.

17. Bernstein DI, Reap EA, Katen K, Watson A, Smith K, Norberg P, Olmsted RA, Hoeper A, Morris J, Negri S, et al: Randomized, double-blind, Phase 1 trial of an alphavirus replicon vaccine for cytomegalovirus in CMV seronegative adult volunteers Vaccine 28: 484-493, 2009.

18. La Rosa C, Longmate J, Lacey SF, Kaltcheva T, Sharan R, Marsano D, Kwon P, Drake J, Williams B, Denison S, et al: Clinical evaluation of safety and immunogenicity of PADRE-cytomegalovirus (CMV) and tetanus-CMV fusion peptide vaccines with or without PF03512676 adjuvant. J Infect Dis 205: 1294-1304, 2012.
19. Wloch MK, Smith LR, Boutsaboualoy S, Reyes L, Han C, Kehler J, Smith HD, Selk L, Nakamura R, Brown JM, et al: Safety and immunogenicity of a bivalent cytomegalovirus DNA vaccine in healthy adult subjects. J Infect Dis 197: 1634-1642, 2008.

20. Sylwester AW, Mitchell BL, Edgar JB, Taormina C, Pelte C, Ruchti F, Sleath PR, Grabstein KH, Hosken NA, Kern F, et al: Broadly targeted human cytomegalovirus-specific CD4+ and CD8+ T cells dominate the memory compartments of exposed subjects. J Exp Med 202: 673-685, 2005.

21. Gratama JW, Boeckh M, Nakamura R, Cornelissen JJ, Brooimans RA, Zaia JA, Forman SJ, Gaal K, Bray KR, Gasior $\mathrm{GH}$, et al: Immune monitoring with iTAg MHC Tetramers for prediction of recurrent or persistent cytomegalovirus infection or disease in allogeneic hematopoietic stem cell transplant recipients: A prospective multicenter study. Blood 116: 1655-1662, 2010

22. Brune W, Hengel $\mathrm{H}$ and Koszinowski UH: A mouse model for cytomegalovirus infection. Curr Protoc Immunol Chapter 19: Unit 19.7, 2001.

23. Wang H, Yao Y, Huang C, Fu X, Chen Q, Zhang H, Chen J, Fang F, Xie $\mathrm{Z}$ and Chen $\mathrm{Z}$ : An adjuvanted inactivated murine cytomegalovirus (MCMV) vaccine induces potent and long-term protective immunity against a lethal challenge with virulent MCMV. BMC Infect Dis 14: 195, 2014.

24. Yazdanian M, Memarnejadian A, Mahdavi M, Motevalli F, Sadat SM, Vahabpour R, Khanahmad H, Soleimanjahi H, Budkowska A and Roohvand F: Evaluation of cellular responses for a chimeric $\mathrm{HBs} A g-\mathrm{HCV}$ core DNA vaccine in BALB/c mice. Adv Biomed Res 4: 13, 2015.

25. Cuburu N, Kweon MN, Song JH, Hervouet C, Luci C, Sun JB, Hofman $\mathrm{P}$, Holmgren J, Anjuère $\mathrm{F}$ and Czerkinsky $\mathrm{C}$ : Sublingual immunization induces broad-based systemic and mucosal immune responses in mice. Vaccine 25: 8598-8610, 2007.

26. Cuburu N, Kweon MN, Hervouet C, Cha HR, Pang YY, Holmgren J, Stadler K, Schiller JT, Anjuère F and Czerkinsky C: Sublingual immunization with nonreplicating antigens induces antibody-forming cells and cytotoxic T cells in the female genital tract mucosa and protects against genital papillomavirus infection. J Immunol 183: 7851-7859, 2009.

27. Wu TC, Guarnieri FG, Staveley-O'Carroll KF, Viscidi RP, Levitsky HI, Hedrick L, Cho KR, August JT and Pardoll DM: Engineering an intracellular pathway for major histocompatibility complex class II presentation of antigens. Proc Natl Acad Sci USA 92: 11671-11675, 1995.

28. Khanna R and Diamond DJ: Human cytomegalovirus vaccine: Time to look for alternative options. Trends Mol Med 12: 26-33, 2006.

29. Doom CM and Hill AB: MHC class I immune evasion in MCMV infection. Med Microbiol Immunol 197: 191-204, 2008.

30. Kim D, Hoory T, Wu TC and Hung CF: Enhancing DNA vaccine potency by combining a strategy to prolong dendritic cell life and intracellular targeting strategies with a strategy to boost CD4+ T cell. Hum Gene Ther 18: 1129-1139, 2007.

31. Nguyen-Hoai T, Kobelt D, Hohn O, Vu MD, Schlag PM Dörken B, Norley S, Lipp M, Walther W, Pezzutto A and Westermann J: HER2/neu DNA vaccination by intradermal gene delivery in a mouse tumor model: Gene gun is superior to jet injector in inducing CTL responses and protective immunity. Oncoimmunology 1: 1537-1545, 2012. 